\title{
Vulnerabilidade a transmissão sexual do vírus da imunodeficiência humana (HIV): representações sociais de universitários indígenas do Instituto Insikiran de formação superior indígena
}

Vulnerability the sexual transmission of the virus of human immunodeficiency $(\mathrm{VIH})$ : social representations of
indian university members of the Insikiran Institute of indigenous higher education

Vulnerabilidad la transmisión sexual del virus de la inmunodeficiencia humana $(\mathrm{VIH})$ : representaciones sociales de universitarios indígenas del Instituto Insikiran de formación superior indígena

Ana Paula Barbosa Alves ${ }^{1 *}$, Baruque Andrade Ramos ${ }^{1}$.

\section{RESUMO}

Objetivo: Analisar as informações, e as atitudes frente a prevenção das infecções sexualmente transmissíveis (ISTs) do vírus da imunodeficiência humana (HIV) e da síndrome da imunodeficiência adquirida (AIDS) e a noção sobre vulnerabilidade entre os estudantes universitários do Instituto Insikiran de Formação Superior Indígena da Universidade Federal de Roraima. Métodos: Trata-se de uma pesquisa de campo, exploratória, de natureza qualitativa, e foi desenvolvida no Insikiran/UFRR em Boa Vista (RR), entre os meses de junho a julho de 2018, a amostra da pesquisa foi composta por 34 alunos matriculados nos três cursos do INSIKIRAN. A técnica de pesquisa utilizada foi à entrevista em que se utilizou um questionário de respostas fechadas e abertas. As respostas dos questionários foram analisadas, a partir das expressões históricas, resultantes de um processo social e de conhecimento. Resultados: Observou-se entre os entrevistados que a maioria refere que utiliza o preservativo e o identificam como um método de prevenção eficaz em relação as infecções sexualmente transmissíveis e o HIV. Porém, em alguns relatos nota-se que o uso do preservativo não é utilizado de modo rotineiro por estes jovens em todas as suas relações sexuais. Conclusão: A maioria dos universitários indígenas possui um elevado índice de conhecimento sobre as formas de transmissão e de prevenção das infecções sexualmente transmissíveis e pelo HIV.

Palavras-chave: Promoção da Saúde, Vulnerabilidade, Saúde Indígena, Universitário.

\begin{abstract}
Objective: To analyze information and attitudes towards the prevention of sexually transmitted infections (STIs) of human immunodeficiency virus (HIV) and acquired immunodeficiency syndrome (AIDS) and the notion of vulnerability among university students of the Insikiran Institute of Indigenous Higher Education of the Federal University of Roraima. Methods: This is an exploratory, qualitative research, developed at the Insituto/UFRR in Boa Vista (RR), between July 2018, a sample of the research was done by 34 students enrolled in the three INSIKIRAN courses. A research technique used for the interview used a closed and open questionnaire. The answers of the questionnaires were analyzed, from the historical functions, resulting from a social process and knowledge. Results: It was noted among the respondents that a majority referred to the use of condoms and was identified as an effective method of combating sexually transmitted infections and HIV. However, in some reports that condom use is not used in a rotating way by these young people in all their sexual relations. Conclusion: Most indigenous universes have a high level of knowledge about the transmission and prevention of sexually transmitted infections and HIV.
\end{abstract}

Key words: Health Promotion, Vulnerability, Indigenous Health, University Students.

${ }^{1}$ Instituto Insikiran de Formação Superior Indígena da Universidade Federal de Roraima. Boa Vista-Roraima.

*E-mail: paula.alves@ufrr.br

SUBMETIDO EM: 1/2019

ACEITO EM: 2/2019

PUBLICADO EM: 4/2019

REAS/EJCH | Vol. 11 (8) | e197 | DOI: https://doi.org/10.25248/reas.e197.2019 Página 1 de 9 


\section{RESUMEN}

Objetivo: Analizar las informaciones y las actitudes frente a la prevención de las infecciones de transmisión sexual (IST) del virus de la inmunodeficiencia humana $(\mathrm{VIH})$ y del síndrome de inmunodeficiencia adquirida (SIDA) y la noción sobre vulnerabilidad entre los estudiantes universitarios del Instituto Insikiran de Formación Superior Indígena de la Universidad Federal de Roraima. Métodos: Se trata de una investigación de campo, exploratoria, de naturaleza cualitativa, y fue desarrollada en el Insikiran / UFRR en Boa Vista (RR), entre los meses de junio a julio de 2018, la muestra de la encuesta fue compuesta por 34 alumnos matriculados en los tres cursos del INSIKIRAN. La técnica de investigación utilizada fue a la entrevista en que se utilizó un cuestionario de respuestas cerradas y abiertas. Las respuestas de los cuestionarios fueron analizadas, a partir de las expresiones históricas, resultantes de un proceso social y de conocimiento. Resultados: Se observó entre los entrevistados que la mayoría refiere que utiliza el preservativo y lo identifican como un método de prevención eficaz en relación a las infecciones sexualmente transmisibles y el VIH. Sin embargo, en algunos relatos se nota que el uso del preservativo no es utilizado de modo rutinario por estos jóvenes en todas sus relaciones sexuales. Conclusión: La mayoría de los universitarios indígenas tienen un alto índice de conocimiento sobre las formas de transmisión y prevención de las infecciones de transmisión sexual y el VIH.

Palabras clave: Promoción de la Salud, Vulnerabilidad, Salud Indígena, Universitarios.

\section{INTRODUÇÃO}

Infecções Sexualmente Transmissíveis (IST) é a nova terminologia que passa a ser adotada em substituição as Doenças Sexualmente Transmissíveis (DST), em consonância com a utilização internacional empregada pela Organização Mundial da Saúde (OMS), pela Organização Pan-Americana da Saúde (Opas), pela sociedade científica e por alguns países pois alerta-se à população pela possibilidade de uma pessoa ter e transmitir uma infecção mesmo sem sinais e sintomas da doença (BRASIL MS, 2015).

As IST mais comuns são: o vírus da imunodeficiência humana (HIV), esse vírus, causador da doença conhecida como AIDS (síndrome da imunodeficiência humana adquirida), ataca o sistema imunológico, responsável por defender o organismo de doenças infecciosas. Ter HIV não é a mesma coisa que ter aids. Há muitas pessoas vivendo com HIV que passam anos sem apresentar sintomas e sem desenvolver a doença. Mas, podem transmitir o vírus a outras pessoas pelas relações sexuais desprotegidas (sexo vaginal, anal e oral); também são ISTs: as Hepatites Virais (B e C), o Papiloma vírus humano (HPV), a Sífilis e a Gonorreia (BRASIL MS, 2018). No Brasil conforme o Sistema Único de Saúde (SUS) por meio do SINAM/DATSUS, informa que aos casos diagnosticados de AIDS em 2017 foram de 8.022, e que de sífilis congênita no mesmo período foram 26.771 casos. Em 2018, foram registrados 63. 421 casos de sífilis em gestantes e em relação as hepatites virais foram notificados 38.887 casos no mesmo período (BRASIL MS, 2019).

Entende-se que a saúde tem suas determinações sociais, econômicas, políticas e culturais que extrapolam as heranças genéticas, a biologia humana, e os fatores ambientais (SOUZA DO et al, 2013). Refletir sobre as vulnerabilidades das populações as doenças, nos leva ao entendimento que a possibilidade de infecção das ISTs/Hiv/Aids, não depende somente das informações e da postura individual, mas de vários fatores relacionados a determinantes que vão muito além da ação patogênica do agente viral específico (AYRES JRCM et al, 2009).

Vale ressaltar que dentro desse perfil epidemiológico atual do HIV/AIDS os jovens vêem contribuindo para o aumento da incidência dessa pandemia os universitários estão enquadrados dentro desse recorte (BRITO AM; CASTILHO EA; SZWARCWALD CL, 2000; BRASIL MS, 2006). Assim, é um pouco controverso, pois supomos que essa população, os estudantes universitários, é teoricamente mais informada, e apresenta-se atualmente, como uma população vulnerável as IST/HIV, e dentro desse conjunto estão os alunos universitários indígenas. 
Observa-se a alta relevância desse estudo devido à elevação do índice das IST/HIV/AIDS nos diferentes grupos sociais; logo, a intenção de abordar temas relativos a esses problemas de saúde entre universitários indígenas para divulgar estes conhecimentos no meio acadêmico é um ato de dever e responsabilidade, contribuindo para transformação sanitária, sociocultural, criando condições propícias para a abordagem da prevenção às ISTs/Hiv/Aids. Assim, essa análise questiona sobre quais são as informações sobre prevenção das ISTs/HIV/Aids, entre os acadêmicos universitários indígenas do INSIKIRAN/UFRR?

Este estudo pretende analisar as informações, e as atitudes frente a prevenção ISTs/HIV/AIDS, e a sua noção sobre vulnerabilidade entre os estudantes universitários do Instituto Insikiran de Formação Superior Indígena da Universidade Federal de Roraima; e identificar as informações dos acadêmicos indígenas sobre as principais infecções sexualmente transmissíveis, e sobre as suas formas de contágio e prevenção.

\section{MÉTODOS}

Trata-se de uma pesquisa de campo, exploratória, de natureza qualitativa. A coleta de dados foi realizada no Instituto Insikiran de Formação superior indígena da Universidade Federal de Roraima localizada na região norte do Brasil. No Instituto Insikiran funcionam três curso de graduação (Licenciatura Intercultural; Gestão Territorial Indígena, Gestão em Saúde Coletiva Indígena) para populações indígenas.

A pesquisa foi desenvolvida entre os meses de junho a julho de 2018. Os sujeitos do estudo foram no total de 34 alunos sendo 20 mulheres e 14 homens, que estão distribuídos nos três cursos do Insikiran na Universidade Federal de Roraima. A escolha dos participantes procedeu-se de forma aleatória.

A formação da amostra foi não-probabilística intencional de acordo com os seguintes critérios de inclusão: ser aluno do Insikiran: estudar em um dos curso do Instituto Insikiran; ter idade de no mínimo de 18 anos e aceitar o convite de participar da pesquisa através do Termo de Consentimento Livre e Esclarecido (TCLE), com a clareza de que a pesquisa poderia acarretar riscos mínimos aos participantes, em relação ao seu psicológico, constrangimento moral, intelectual, social, cultural ou espiritual. Este estudo foi submetido ao comitê de ética da Universidade Federal de Roraima e enviado à Comissão Nacional do Comitê de Ética (CONEP) e recebeu o parecer consubstanciado de aprovado por meio do número: 2.750.644.

A técnica de pesquisa utilizada para o levantamento de dados foi uma entrevista em que se utilizou um questionário com 18 perguntas, e respostas fechadas e abertas. A abordagem para interpretação dos dados foram as análises das respostas dos questionários, em que buscou-se apreender as expressões históricas, resultantes de um processo social e de conhecimento.

\section{RESULTADOS}

\section{Caracterização dos Participantes do Estudo}

A população alvo do estudo contou com 34 estudantes, em que apresentavam-se na faixa etária entre 20 a 42 anos, e já eram universitários a mais de três anos (73,5\%); com renda familiar de um salário mínimo. Em relação ao gênero: feminino foram $58,8 \%$, masculino foram $41,1 \%$. As principais etnias foram: Macuxi (58,8\%), Wapixana (32.3\%), Taurepang (5,8\%), Ingarikó (2,9\%). A maioria não trabalha $94,1 \%$, e dois trabalham $(5,88 \%)$. A maioria que corresponde a $64,7 \%$ dos entrevistados vivem na cidade com a família ou amigos durante a semana de aula e no final da semana retornam as suas comunidades. E apenas $35,3 \%$ conseguem estudar na universidade que está localizada em Boa Vista-RR e voltar as suas comunidades indígenas todos os dias.

\section{Atividade Sexual}

Em relação a frequência da atividade sexual e ao estado civil observa-se na tabela 1 que dos 34 entrevistados: $73,5 \%$ é ativo sexualmente e refere uma frequência semanal, e $26,5 \%$ refere uma frequência 
diária. A maioria $58,8 \%$ refere viver junto a um companheiro(a), $23,5 \%$ são solteiros e $17,6 \%$ se declaram casados.

Tabela 1 - Frequência da atividade sexual e categorias.

\begin{tabular}{cc}
\hline Frequência & Quantidade em \% \\
\hline Semanal & 73,5 \\
Diária & 26,5 \\
Categoria & Quantidade em \% \\
Casado & 17,6 \\
Solteiro & 23,5 \\
Junto & 58,8
\end{tabular}

Fonte: Dados da pesquisa, 2018.

A tabela 2 diz respeito ao início da atividade sexual: 5,8\% referem que foi antes dos 10 anos de idade, $14,7 \%$ referem que foi entre 10 a 15 anos de idade, e $79,4 \%$ referem que sua primeira atividade sexual entre 15 a 20 anos de idade.

Tabela 2 - Início da vida sexual.

\begin{tabular}{cc}
\hline Início & Total em \% \\
\hline Antes dos 10 anos & 5,8 \\
Entre 10 a 15 anos & 14,7 \\
Entre 15 a 20 anos & 79,4 \\
\hline
\end{tabular}

Fonte: Dados da pesquisa, 2018

\section{Ter Realizado alguma vez na vida o teste para o HIV}

Pode-se notar na tabela 3 a condição sorológica em relação ao HIV: 85,2\% dos entrevistados já fizeram o exame (teste-rápido para o HIV) e 14,8\% nunca realizaram nenhum tipo de exame sobre o HIV. Questionando o motivo que os levaram a fazer o teste: $41,1 \%$ refere ter feito devido ao período de exames do pré-natal, que pendem o exame como rotina, $23,5 \%$ o fizeram por curiosidade, $23,5 \%$ fizeram por ter mantido um comportamento de risco, e $11,7 \%$ o fizeram devido ter ido doar sangue.

Tabela 3 - Condição sorológica em relação ao HIV.

\begin{tabular}{cc}
\hline Realização de testes rápidos & Quant. Em \% \\
\hline Já realizaram & 85,2 \\
Nunca fizeram & 14,8 \\
Motivo para realizar o teste & \\
Pré - Natal & 41,1 \\
Curiosidade & 23,5 \\
Doador de sague & 23,5 \\
Comportamento de risco & 11,7 \\
\hline
\end{tabular}

Fonte: Dados da pesquisa, 2018. 
A maioria dos entrevistados $85,2 \%$ já tiveram mais de dois parceiros sexuais na vida, e $14,8 \%$ referem que até o momento só tiveram um parceiro sexual na vida. E 8,8\% referem ter ingerido bebida alcoólica antes das relações sexuais, e 91,1\% refere nunca ter consumido bebidas alcoólicas antes das relações sexuais.

\section{Uso do preservativo nas Relações Sexuais}

A respeito do uso do preservativo em todas as relações sexuais com parceiros fixos e eventuais: $50 \%$ referem o uso do preservativo em todos os tipos de relações sexuais com parceiros fixos ou eventuais, $47 \%$ referem o uso do preservativo com os parceiros sexuais eventuais, e 2,9\% dos entrevistados refere nunca usar o preservativo nem com parceiros fixos ou eventuais em suas relações sexuais.

A metade dos entrevistado, entorno de $50 \%$, afirmam que o uso de preservativos masculinos e femininos é a melhor maneira de evitar as infecções sexualmente transmissíveis/HIV. Assim, $47 \%$ acreditam que ter parceiro fiel e não infectado reduz o risco de transmissão do HIV, para os mesmos o uso do preservativo nas relações sexuais só os protegem se o parceiro(a) for eventual, pois não precisa usar preservativo com parceiro fixo, e 3\% não acredita na proteção do preservativo quanto as IST/HIV. E 97\% dos entrevistados concordam que uma pessoa pode ser infectada nas relações sexuais sem preservativo.

\section{Conhecimento correto sobre formas de transmissão e prevenção da infecção pelo HIV}

Aproximadamente $70 \%$ dos indivíduos concordam que não podem ser infectados por picada de inseto; 94\% concordam que uma pessoa com aparência saudável pode estar infectada pelo HIV ou outras infecções sexualmente transmissíveis e $90 \%$ dos indivíduos sabiam que podem ser infectados pelo HIV ao compartilhar seringas.

$\mathrm{Na}$ tabela 4, ressalta a questão do conhecimento correto de formas de transmissão das infecções sexualmente transmissíveis/HIV, estabelecido pelo acerto de cinco questões, o percentual obtido pelos acadêmicos de 20 a 45 anos foi de $57 \%$. Por outro lado, nota-se que em torno de vinte e quatro (70\%) dos acadêmicos entrevistados acreditam que uma pessoa pode ser infectada pelo HIV ao compartilhar talheres, e $20(58,8 \%)$ acreditam que podem infectar-se ao usar banheiros públicos. Em torno de $70 \%$ dos acadêmicos entrevistados de 20 a 42 anos sabiam que uma gravida que recebe tratamento adequado durante a gravidez e o parto, diminui o risco de transmissão do HIV para seu filho.

Tabela 4 - Percentual (\%) de Universitários Indígenas com idade entre 20 e 42 anos, com conhecimento correto sobre formas de transmissão e prevenção da infecção pelo HIV. Boa Vista -RR, jun-jul de 2018.

\begin{tabular}{ll}
\hline Concordam com as afirmativas & $\%$ N (34) \\
\hline Uma pessoa com aparência saudável pode estar infectada pelo HIV & $94 \%(31)$ \\
Ter parceiro fiel e não infectado reduz o risco de transmissão do HIV & $47 \%(16)$ \\
O uso de preservativo é a melhor maneira de evitar a infecção pelo HIV & $50 \%(17)$ \\
Uma pessoa não pode ser infectada ao ser picada por um inseto & $70 \%(24)$ \\
Uma pessoa não pode ser infectada pelo compartilhamento de talheres & $70 \%(24)$ \\
Uma pessoa não pode ser infectada em banheiro público & $58,8 \%(20)$ \\
Uma pessoa pode ser infectada ao compartilhar seringa & $90 \%(30)$ \\
Uma pessoa pode ser infectada nas relações sexuais sem preservativos & $97 \%(33)$ \\
Não existe cura para AIDS & $97 \%(33)$ \\
Uma grávida que recebe tratamento adequado durante a gravidez e o parto diminui o & $70 \%(24)$ \\
risco de transmissão do HIV para o filho &
\end{tabular}

Fonte: Dados da pesquisa, 2018.

REAS/EJCH | Vol. 11 (8) | e197 | DOI: https://doi.org/10.25248/reas.e197.2019 Página $\mathbf{5}$ de $\mathbf{9}$ 
Nos resultados supracitados na tabela 4 a respeito dos conhecimentos sobre a formas de transmissão e prevenção da infecção pelo HIV, observa-se que existem equívocos, como por exemplo, 16 (47\%) dos estudantes entrevistados acreditam que ter parceiro fiel e não infectado reduz o risco de transmissão do HIV. Porém, a maioria (50\%), dos participantes do estudo demostram que a maioria dos universitários indígenas possui um correto conhecimento sobre as formas de transmissão e de prevenção das infecções sexualmente transmissíveis e pelo HIV. Vale ressaltar, que isso está relacionado, especialmente, ao nível de reconhecimento do uso do preservativo como a melhor forma de evitar a infecção pelo HIV. O preservativo é bastante conhecido como um método de prevenção eficaz.

\section{DISCUSSÃO}

Em relação ao início da atividade sexual entre os sujeitos do estudo. Pode-se refletir, conforme alguns estudos que estes resultados contribuem para o entendimento que estes jovens adultos têm sua iniciação sexual muito precocemente, o que pode causar sua exposição a problemas de saúde (LARA LAS; ABDO, $\mathrm{CHN}, 2015)$. Corrobora com essas afirmações a "Pesquisa de Conhecimentos, Atitudes e Práticas relacionadas às IST e Aids na População Brasileira de 15 a 64 anos" (PCAP), segundo a qual um quarto da população brasileira iniciou a atividade sexual antes dos 15 anos, e outros $35 \%$, entre 15-19 anos. Além disso, quase $30 \%$ da população de 15 a 49 anos relataram ter múltiplas parcerias no ano anterior à pesquisa (mais de uma parceria sexual), sendo $47 \%$ entre os homens e $18 \%$ entre as mulheres (BRASIL MS, 2018).

Observa-se entre os entrevistados que a maioria refere que utiliza o preservativo e os identificam como um método de prevenção eficaz em relação as infecções sexualmente transmissíveis e o HIV. Porém em alguns relatos nota-se que o uso do preservativo não é utilizado de modo rotineiro por estes jovens, pois quando o parceiro é eventual até que o uso chega a quase $50 \%$ dos casos, e vai se tornando um hábito esporádico e as vezes raro quando o parceiro é fixo, pois existe uma credibilidade de fidelidade e proteção ao HIV, quando a parceria se torna fixa. A eficácia do preservativo como forma de prevenção as ISTs/HIV, para cada caso individual, dependerá fundamentalmente da frequência que é utilizado em todas as relações sexuais (SILVA AT et al, 2015).

Segundo Fontes MB et al (2017), os jovens apesar de fazerem uso do preservativo nas relações sexuais em maior nível que os segmentos populacionais com idade mais avançada, ainda não incorporaram o seu uso de forma regular, mostrando que são um grupo vulnerável em relação ao comportamento sexual e a outras determinantes socioecômicos. Vários fatores contribuem para essa incidência do HIV entre os jovens, como podemos citar: urbanização desorganizada; a violência social; condições econômicas precárias; falta de informações sobre sexo e sexualidade; migrações; prostituição; turismo sexual e o uso distorcido dos meios de comunicação de massa (TAQUETTE SR et al, 2015).

O uso do preservativo é a única forma de prevenção efetiva para as IST/HIV para uma população sexualmente ativa. $\mathrm{E}$ as ações de prevenção devem estar pautadas em informações e educação que incentivem a prática do sexo seguro, ou seja, pelo uso do preservativo masculino e feminino em todos os tipos de relações sexuais. O Ministério da Saúde, aumentou a distribuição de preservativos, passando de 202 milhões de unidades em 2005 para 493 milhões de unidades em 2011, sendo os jovens os usuários que mais retiram preservativos no SUS (TEIXEIRA MG et al, 2014). Mas, apesar do aumento da frequência do uso de preservativo entre os jovens, a utilização habitual ainda não é uma realidade em seu cotidiano, principalmente nas relações eventuais e não programadas, denotando aí um comportamento de risco (CASTRO CM; SILVA MA, 2013).

Almeida RAAS et al (2017) referem que as informações sobre IST é um assunto que faz parte dos interesses da juventude, e que a maior parte reconhece a forma adequada de prevenção dessas enfermidades, que seria o uso do preservativo em todos os tipos de relações sexuais. Porém, o uso efetivo do preservativo envolve vários fatores, em que o conhecimento sobre prevenção não é suficiente. Portanto, faz-se necessário entender que este processo sofre influência das dimensões históricas e culturais dos sujeitos envolvidos, os quais dão sentido as suas atitudes que podem ou não ser experiências seguras em

REAS/EJCH | Vol. 11 (8) | e197 | DOI: https://doi.org/10.25248/reas.e197.2019 Página 6 de $\mathbf{9}$ 
suas práticas sexuais. Neste sentido, o conceito de vulnerabilidade pode instrumentalizar as políticas e programas dos serviços de saúde principalmente nas ações de prevenção, proteção e promoção da saúde.

O conceito de vulnerabilidade está relacionado aos fatores estruturais da sociedade, que se refere à desigualdade de renda, educação e de acesso à serviços; as relações de gênero, étnicas, afetivas, geográficas e na esfera da significação. Essa característica multidimensional da vulnerabilidade que emerge nos anos de 1980, especificamente na área da saúde, entende-se como uma possibilidade ou alternativa para entender à epidemia da Aids na perspectiva de desconstruir a tendência individualizante da doença (SÁNCHES AIM; BERTOLOZZI MR, 2007).

Assim, a vulnerabilidade procura contestar a percepção de que a chance de exposição das pessoas pelo HIV e ao padecimento pela AIDS (ou outras doenças) depende apenas dos aspectos individuais, todavia envolve fatores no âmbito das estruturas coletivas e contextuais, que originam de forma máxima ou mínima a disponibilidade as infecções e ao padecimento de maneira intrínseca (AYRES JRCM et al, 2012).

A pandemia da AIDS está presente em diferentes momentos, regiões e em populações humanas diversas, e permanece como um dos principais problemas de saúde pública do Brasil (MEDRONHO RA, 2009; ÁVILA $\mathrm{T}, 2014)$.

Os modos sobre as formas de transmissão sexual do HIV são crenças e avaliações relativas à AIDS, e orientam as condutas preventivas dos jovens. Sabe-se que a relação entre a informação e a ação (atitude) não tem um único sentido. Estudos mostram que o uso do preservativo é um comportamento complexo que envolve tanto significados, sentidos, símbolos, como aspectos afetivos e sexuais (CASTRO CM; SILVA MA, 2013).

Igualmente, os jovens devem racionalizar, orientados para comportamentos preventivos, pois se não pensarem que devem ter uma atitude de prevenção em todas as suas relações sexuais, o seu comportamento nunca vai refletir o seu agir, pois não está ainda internalizado, como algo que deve ser feito para sua saúde em seu cotidiano. Ao contrário observa-se que a maioria dos jovens usam o preservativo só quando é possível ou quando for claramente em situações que os coloque em risco (MONTEIRO S, 2002).

Nesse sentido, refletir sobre os aspectos psicossociais e culturais da AIDS leva a implicações importantes, particularmente na saúde indígena, para as práticas de promoção da saúde, especificamente de prevenção do HIV/AIDS, bem como para o cuidado dos jovens. Desta forma, a única forma de evitar uma IST e o HIV, é fazer o uso da camisinha em todas as relações sexuais, o que se configura em um grande desafio.

Para essa questão pode-se pensar em alternativas educacionais com vistas a promoção da saúde, em que se busque atividades e ações tanto pela academia e pelos serviços de saúde, no sentido da valorização da vida e na construção das alternativas de prevenção num clima de liberdade, responsabilidade e solidariedade humana. Ressalta-se que adentrar no campo da intimidade e sexualidade não é uma tarefa fácil, mas não é impossível, basta que todos os envolvidos notem a importância dessas ações de prevenção para sua qualidade de vida individual e coletiva (MONTEIRO S, 2002).

Assim sendo, não custa nada reforçar e alertar que a única maneira de prevenir as ISTs e o Hiv/Aids, em uma população sexualmente ativa é por meio de informação e educação que se esclareça a prática do sexo seguro. Além de falar sobre o uso do preservativo masculino e/ou feminino em todas as relações sexuais para a população em geral, se faz necessário refletir sobre os aspectos das vidas das pessoas, em que elas mesmas percebam e analisem os possíveis riscos a que estão expostas nas práticas sexuais.

Do mesmo modo, todas as instituições de educação e de saúde públicas, como as escolas e as universidades e o Sistema Único de Saúde, necessitam formar, mudar e elaborar estratégias para apoiar a população em geral, no sentido que as mesmas possam aprender que qualquer pessoa está sujeita à contaminação, de forma complexa, pois cada segmento social tem as suas especificidades, que dependem de suas características econômicas, sociais e culturais. Diminuir as condições de vulnerabilidade dos jovens as IST/HIV, permanece ainda hoje um dos mais enormes desafios do trabalho de prevenção (CASTRO, CM; SILVA MA, 2013). 
A pandemia da AIDS é uma realidade social que afeta homens, mulheres e crianças e sua abordagem tem como objetivo as ações de educação em saúde (TEIXEIRA MG et al, 2014). E muitas áreas do conhecimento científico buscam construir estratégias para seu enfrentamento. É um problema contemporâneo, teve sua história natural construída pela contribuição do senso comum e da ciência, e por essa razão, estudar as concepções sobre vulnerabilidade, e informações sobre prevenção as ISTs/HIV/Aids, entre os acadêmicos universitários indígenas da UFRR, instigou a reflexão e o debate de maneira dialógica sobre aspectos individuais, e coletivos, entre outros, na busca por mudança e melhor qualidade de vida para os jovens universitários indígenas.

\section{CONCLUSÃO}

Neste estudo em relação os acadêmicos indígenas a diversidade cultural é um fator que deve ser compreendido no sentido de minimizar os riscos e favorecer as atitudes preventivas. A atitude de prevenção das ISTs não é algo simples para populações não-indígenas, imagina para os povos indígenas que apresentam uma visão de mundo e cultura diversa, é algo complexo que envolve um cenário histórico delicado e polissêmico. É notório que o HIV/AIDS atinge os diversos povos indígenas do Brasil e como povos diferenciados apropriam-se dessa problemática estabelecendo-a em seus próprios sistemas de mundo e circunstâncias socioculturais, e para estes povos é consequência dos contatos interétnicos. Mas, deve-se buscar junto as comunidades indígenas e suas lideranças soluções para se promover saúde e prevenir essas infecções que causam um impacto tanto social quanto psicológico nos indivíduos e seus familiares, procurando relativizar seus conhecimentos sobre sexualidade e suas organizações sociopolítica e culturais como também como reconhecem o processo saúde-doença e cuidado. Desta maneira, vale pensar que os serviços de educação e promoção da saúde tenham uma atuação dialógica, participativa, que saiba o valor a diversidade de saberes, de cultura e ao trabalho em equipe, que busque a parceria da comunidade, que fortaleça e crie vínculos, que busque ações intersetoriais, no sentindo de fomentar a proteção e promoção da saúde da população que assiste, e que consiga diminuir e combater as vulnerabilidades e as iniquidades sociais.

\section{AGRADECIMENTOS}

Agradeço a todos que direta e indiretamente colaboraram com o estudo, e ao Instituto Insikiran de Formação Superior Indígena da UFRR, por todo apoio logístico que possibilitou a realização da pesquisa.

\section{REFERÊNCIAS}

1. ALMEIDA RAAS, et al. Conhecimento de adolescentes relacionados às doenças sexualmente transmissíveis e gravidez. Rev Bras Enferm. 70(5):1087-94. 2017.

2. ÁVILA T. Cultura, Sexualidade e Saúde Indígena: etnografia da prevenção das DST/Aids nos povos Timbira do Maranhão e do Tocantins. In: TEIXEIRA, C C (Org.). Saúde Indígena em Perspectiva: explorando suas matrizes históricas e ideológicas. Rio de Janeiro: Editora FIOCRUZ, 2014. 241-261 p. ISBN: 978-85-7541-449-1.

3. AYRES JRCM, et al. Risco, Vulnerabilidade e Práticas de Prevenção de Promoção da Saúde. In: CAMPOS, GWS et al. Tratado de Saúde Coletiva. $2^{a}$ ed. rev. aum. São Paulo: Hucitec, 399-442 p. 2012. ISBN: 978-85-64806-56-6.

4. AYRES JRCM, et al. O Conceito de Vulnerabilidade e as Práticas de Saúde: novas perspectivas e desafios. In: CZERESNIA D, FREITAS CM (Org.). Promoção da saúde: conceitos, reflexões, tendências. 2. ed. rev. e amp. p. 121-143. Rio de Janeiro, Editora Fiocruz, 2009. ISBN: 978-85-7541-183-4.

5. BRASIL. Ministério da Saúde. Departamento de Informática do SUS (DATASUS), 2019.

6. BRASIL. Ministério da Saúde. Homens Trans: vamos falar de prevenção de infecções sexualmente transmissíveis. 2018. 19-24 p. 48 p.

7. BRASIL. Ministério da Saúde. Protocolo Clinico e Diretrizes Terapêuticas para Atenção Integral as Pessoas com Infecções Sexualmente Transmissíveis. Brasília: Ministério da Saúde, 2015. p. 13-27. 120 p. ISBN 978-85-334-23527. 
8. BRASIL. Ministério da Saúde. Pesquisa entre Conscritos do Exército Brasileiro 1996-2002: Retratos do comportamento de risco do jovem brasileiro à infecção pelo HIV. Brasília: Ministério da Saúde. 2006. 128p.

9. BRITO AM, CASTILHO EA, SZWARCWALD CL. AIDS e infecção pelo HIV no Brasil: uma epidemia multifacetada. Rev. Soc. Bras. Med. Trop. [online]. 2001, vol.34, n.2 [cited 2019-02-02], pp.207-217. ISSN 00378682.

10. CASTRO CM, SILVA MA. O comportamento dos adolescentes frente ao risco de contaminação com HIV/AIDS. Estudos [Internet]. Estudos, Goiânia, v. 40, n. 4, p. 395-418, out./dez. 2013.

11. FONTES MB et al. Fatores determinantes de conhecimentos, atitudes e práticas em DST/Aids e hepatites virais, entre jovens de 18 a 29 anos, no Brasil. Ciência \& Saúde Coletiva, 22 (4):1343-1352. 2017. DOI: 10.1590/141381232017224.12852015.

12. LARA LAS, ABDO CHN. Aspectos da atividade sexual precoce. Rev Bras Ginecol Obstet. 37(5):199-202. 2015.

13. MEDRONHO RA et al. Epidemiologia. São Paulo: Editora Atheneu, 2009. ISBN. 978-85-7379-999-6.

14. MONTEIRO S. Qual prevenção? Aids, sexualidade e gênero em uma favela carioca [online]. Rio de Janeiro: Editora FIOCRUZ, 2002, 145 p. ISBN: 978-85-7541-521-4.

15. SÁNCHES AIM; BERTOLOZZI MR. Pode o conceito de vulnerabilidade apoiar a construção do conhecimento em Saúde Coletiva? Ciência \& Saúde Coletiva, 12 (2): 319-324, 2007.

16. SILVA AT et al. Conhecimento de adolescentes do ensino médio sobre DST/AIDS no sul do Brasil. Aletheia, Canoas, n. 46, p. 34-49, abr. 2015.

17. SOUZA DO et al. Determinantes Sociais da Saúde: reflexões a partir das raízes da "questão social" Saúde Soc. São Paulo, v.22, n.1, p.44-56, 2013.

18. TAQUETTE SR et al. Infecção pelo HIV em adolescentes do sexo masculino: um estudo qualitativo. Ciência \& Saúde Coletiva, 20(7):2193-2200. 2015. DOI: 10.1590/1413-81232015207.18102014.

19. TEIXEIRA MG et al. Prevenção, atenção e controle de doenças transmissíveis. In: PAIM, J S; ALMEIDA-FILHO, N. Saúde Coletiva: teoria e prática. 1 ed. Rio de janeiro: Medbook. 401-422 p. 2014. ISBN: 978-85-99977-97-2. 